\title{
Pesquisa em polímeros no XXIII Encontro Nacional de Física da Matéria Condensada
}

Um dos grandes temas explorados anualmente no Encontro Nacional de Física da Matéria Condensada - ENFMC é o de Sistemas Complexos, englobando pesquisas em polímeros e fluidos complexos. Apesar de o Encontro abrigar tradicionalmente apenas uma pequena parcela da comunidade de polímeros no Brasil, constituída principalmente por físicos, uma grande variedade de tópicos é abordada. O XXIII ENFMC, realizado em São Lourenço (MG), de 9 a 13 de maio de 2000, não foi exceção. Foram apresentadas palestras orais e posters em tópicos tão diversos quanto a simulação teórica, usando dinâmica molecular, para explicar propriedades elétricas de polímeros, até a aplicação em protótipos de dispositivos utilizando polímeros condutores e cristais líquidos.

Mais especificamente, foram tratados: polímeros condutores e suas aplicações em narizes eletrônicos, propriedades eletroluminescentes de polímeros e blendas, fabricação de superestruturas na forma de filmes Langmuir-Blodgett (LB), propriedades de superfícies carregadas, características estruturais de fil- mes poliméricos, ferrofluídos, fluídos magnéticos e cristais líquidos. A caracterização de propriedades específicas de polímeros convencionais por técnicas como SAXS e RMN também foi um tema abordado.

Outro destaque do Encontro foi a presença de convidados estrangeiros, diretamente relacionados a grupos de pesquisa de polímeros no Brasil. O Dr. Ray Baughman, da Allied Signal, EUA, um dos editores da revista Synthetic Metals, apresentou a recente descoberta da utilização de nanotubos de carbono para produção de músculos artificiais. O Prof. Mark Robbins, da Universidade Johns Hopkins, EUA, discutiu aspectos de falhas de adesão. O Prof. Phil Pincus, Universidade da Califórnia, Santa Barbara, EUA, fez uma revisão da física envolvida em superfícies altamente carregadas, com exemplos de biopolímeros como o DNA. Embora tenha apresentado uma palestra convidada no tema de Biofísica, o Prof. Mathias Lösche, da Universidade de Leipzig, Alemanha, também atua em polímeros, com destaque para o emprego de algoritmos genéticos para a determinação das possíveis conformações de um polímero na interface água-ar.

Notícia elaborada por Marysilvia Ferreira, UFRJ/COPPE-PEMM e Osvaldo N. Oliveira J r., USP/Instituto de Física de São Carlos. 